\title{
Authentic dining experiences of ethnic Asian cuisine restaurant customers in Camarines Sur
}

\author{
Illo, Norel Peter $\$ \\ Lyceum of The Philippines University - Batangas, Philippines (norelillo@gmail.com) \\ Received: 5 December 2020 \\ Available Online: 15 January 2021 \\ Revised: 22 December 2020 \\ DOI: $10.5861 /$ ijrsm.2021.7703
}

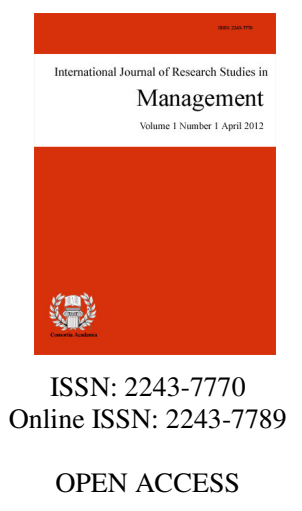

\section{Abstract}

The study focused on the customers' perceived authentic dining experiences in terms of authenticity, physical environment, food quality, and service quality. Descriptive type of research method with adopted and adopted survey questionnaire was used in in the study. The customer-respondents are very satisfied with the food authenticity in terms of authenticity, Neat and well-dressed employees in terms of physical environment. The customers-respondents are very satisfied with the overall food quality and service quality of the Asian restaurants in Camarines Sur. Current dining place in Japanese restaurants significantly affects the authentic dining experiences of the customers and there is a significant difference on the customers' authentic experience in terms of number of visits in food quality and service quality. There is also a significant difference on the customers' authentic experience in terms of dining expenses in service quality. Restaurateurs of authentic ethnic Asian cuisine restaurants may improve their dining experiences in terms of Authenticity and Physical environment because these are core attributes in an overall authentic dining experience of the customers. Providing an extra mile on their services may exceed the customer expectation and satisfaction by improving their responsiveness. They may also give more information about the drinks they are offering since customers are not much into the drinks. Restaurateurs must also identify what music could suit their customer's tastes. Sending employees to a service quality related training seminar may help improve the standards in operating the business.

Keywords: authentic ethnic Asian cuisine restaurant; food tourism; authentic experience; dining factors; post-purchase intentions 


\section{Authentic dining experiences of ethnic Asian cuisine restaurant customers in Camarines Sur}

\section{Introduction}

The demand for Asian restaurants has increased significantly. Scholars identified elements that contribute to the restaurant's overall success; however, it is unclear if these factors also affect ethnic restaurants. Ethnic cuisine restaurateurs found out that competent management and having loyal customers was the most critical contributor to success (Agarwal \& Dahm, 2015). Customer dining experiences are essential for the service industry, as it is influenced by the quality of the relationship between the restaurant and the customers. The customer expectations for excellent services are continually changing that serve as an opportunity for all the restaurants to provide an exceptional experience for future development. A customer-centered strategy is significantly important for any restaurant industry since customers' perceptions depends on the service process used by restaurant employees and companies (Ingerson \& Kim, 2016).

Ethnic food is believed to bring aroma and flavor to customers in a country that is looking forward to visiting. According to Kim (2018), Travelers tend to search for foods they've tried in a particular country, in restaurants and ethnic markets or try cooking dishes they miss in their kitchen with the help of recipe books. Consumers like to eat in ethnic restaurants because Customers want to try new flavors and get acquainted with other cultures. Consumers are expected to have varied experiences while eating at foreign cuisine restaurants. Zhong and Moon (2020) identified three main components to determine the quality of the restaurant: Food, physical environment, and service to employees. Authentic food is defined as the expression of culture, area, or population - Food has been found to act as a medium that almost instantly builds a relationship with the Customers that can give them the authentic cultural feeling (Higgs \& Thomas, 2016).

The study of Nam et al. (2017) shows that the quality of food has directly and significantly influenced the perceived value and satisfaction. Furthermore, the perceived value was more influenced by the quality of the food. Current findings imply that Asian cuisine vendors, such as Japanese, Chinese and Korean ethnic restaurants, should pay more attention to improving food quality, which increases perceived value and satisfaction and, in turn, can lead to revision and recommendations. Physical environment influences customers' perceived value and dining factor that affects post-purchase intentions among customers (Han \& Hyun, 2017; Omar et al., 2015). Han and Ryu (2007) emphasized that "décor, artifacts, spatial layout and ambient conditions affect post-purchase intentions among customers". Jang and Namkung (2009) noted that "atmospherics foster positive post-purchase intentions."

The researcher observed that there are many Asian restaurants emerging in Camarines Sur; many customers patronizing these restaurants and these customers keep on coming. The researcher wanted to know the authentic dining experiences that will meet and exceed customer satisfaction. Authentic experiences, of the authentic Asian cuisine restaurant serve is the main agenda of this paper. This study can be beneficial to improve the services among the Asian Restaurants and the economic programs and growth of tourism in the Camarines Sur area. The findings are also expected to be of significant assistance to the restaurant sectors of the region, mainly the businesses which offer Asian cuisine.

\subsection{Objective of the study}

This study intended to assess the Asian Cuisine Restaurants in Camarines Sur that will enhance the authenticity of the Asian restaurant. More specifically, this study sought to determine the authentic dining experiences in terms of Authenticity, Physical Environment, Quality of Food, and Service Quality and to test the significant differences in the authentic experiences when grouped according to their demographic profile. 


\section{Methods}

The descriptive method of research is a fact-finding study that substantially and correctly interprets the results of an investigation. Through exploration and analysis, this method is significantly applied to this study because it determines the authentic dining experiences of the customer-respondents in dining in an Asian cuisine restaurant. This study tapped 348 Asian cuisine restaurant customers from Camarines Sur using random sampling. The proponent seeks the permission of the owners/managers/supervisors of the restaurants' understudy and requests to allow their customers to answer the survey questionnaire.

\section{Table 1}

Profile of the authentic Asian customers

\begin{tabular}{|c|c|c|c|}
\hline Profile & Category & Frequency & Percent \\
\hline \multirow[t]{2}{*}{ Current Dining Place } & Chinese & 136 & 39.1 \\
\hline & Japanese & 48 & 13.8 \\
\hline \multirow[t]{3}{*}{ Preference: Korean } & First & 200 & 57.5 \\
\hline & Second & 100 & 28.7 \\
\hline & Third & 48 & 13.8 \\
\hline \multirow{2}{*}{ Preference: Chinese } & Second & 135 & 38.8 \\
\hline & Third & 145 & 41.7 \\
\hline \multirow[t]{3}{*}{ Preference: Japanese } & First & 81 & 23.3 \\
\hline & Second & 118 & 33.9 \\
\hline & Third & 148 & 42.5 \\
\hline Reason for Visit & Other & 20 & 5.7 \\
\hline \multirow[t]{6}{*}{ Number of Visit } & One & 59 & 17.0 \\
\hline & Two & 67 & 19.3 \\
\hline & Three & 47 & 13.5 \\
\hline & Four & 23 & 6.6 \\
\hline & Five & 30 & 8.6 \\
\hline & More Than 5 & 122 & 35.1 \\
\hline \multirow[t]{3}{*}{ Dining Expenses } & Less than 1,000 & 186 & 53.4 \\
\hline & $>1,000<2,000$ & 91 & 26.1 \\
\hline & $>2,000<3.000$ & 50 & 14.4 \\
\hline
\end{tabular}

Table 1 presents the profile of the authentic Asian customers. From the result of the current dining place, most of the customers dined at Korean restaurants with a total of 164 (47.1 percent) followed by Chinese restaurants with 136 (39.1 percent) and the least is the Japanese restaurants with 48 respondents (13.8 percent). Based from this result, this can be gleaned that there are more Korean Restaurants in Camarines Sur compared to the other. In terms of cuisine preference in authentic Asian cuisine, out of 248 respondents, 57.5 percent (200) ranked Korean first, 28.7 percent (100) ranked it second and 13.8 percent (48) ranked it third. And for Chinese preference, out of 248 respondents, 19.5 percent ranked it first, 38.8 percent ranked it second, and 41.7 percent ranked it third. Lastly, for Japanese preference, out of 248 respondents, 23.3 percent ranked it first, 33.9 percent ranked it second, and 42.5 percent ranked it third.

The ranking of their preference may be due to the influence that the advent of $\mathrm{K}$ pop culture has on them as well as the presence of many Koreans in some parts of the country to study English. Chinese cuisine is the respondents' second choice. This may be attributed to the fact that more Chinese people are coming in the country. The food that they have introduced to the people then and in the contemporary years, have captured the fancy of the Filipinos, and the interest in the said cuisine has paved the way for businessmen to open Chinese restaurants that offer authentic food that many have learned to love. 
Out of 348 respondents, 58 percent (202) answered that Leisure are their reason for visiting; 23.6 percent (82) are visiting their friends and Relatives; 8.6 percent visits for business; 5.7 percent (20) visits for other reasons and; 4 percent (14) visits for seminar. This clearly implies that most of the respondents visit Asian restaurants for the purpose of leisure. Customers tend to dine in a restaurant for family bonding, recreation, and relaxation. Escaping, seeking, experiential authenticity and resistance are potential factors driving Customers' behavior. Customers may escape routine environments and seek intrinsic rewards for personal and interpersonal reasons. Also, it has been suggested that Customers may seek authenticity when they travel. This study focuses on existential authenticity. Existential authenticity deals with the Customers' experiences including social and cultural dimensions that can signify a "state of being" (Cohen, 2010), such as being "released from the alienating conformity to the pressures of the contemporary consumer society". Experience-based authenticity may have nothing to do with the actual authenticity of a toured object (Ayer et al., 2016).

From 348 respondents, most of the respondents visit more than 5 times in a restaurant with (35.1 percent), 19.3 percent visit 2 times, 17 percent visit 1 time, 13.5 percent visit 3 times, 8.6 percent visit 5 times and the least of the respondents visit for 4 times with 6 percent. The dining expense profile was only confined to four categories due to limited response for 4,000 and above. Out of 348 respondents, 53.4 percent spent less than $1,000,26.1$ percent spent $>1,000<2,000,14.4$ percent spent $>2,000<3,000$, and 6 percent spent $>3,000$.

The researcher administered an adopted questionnaire from different research. The first part is about the profile of the respondents; second refers to the authentic dining experiences in terms of Authenticity, Physical Environment, Quality of Food, and Service Quality; with Values for Cronbach's were 0.889, 0.889, 0.892, and 0.900 for the Authentic Experiences (Muskat et al., 2019). The researcher tested the reliability of the instrument before proceeding to data gathering. The proponent identifies the restaurants' understudy through formal visitation and personally ask the restaurants' owners/managers/supervisors/persons in-charge for their consent to conduct the study and agree that their customers' responses would be treated with the utmost confidentiality. Pertinent sites were also consulted to identify the location of the restaurants easily like consulting to the Department of Tourism office to give the list of Authentic Asian cuisine restaurants in Camarines Sur. The questionnaires were formally distributed, administered, and retrieved on the same day using convenience sampling. Due to the pandemic, the researcher also used Google Forms to distribute questionnaires online since there is a strict implementation of social distancing. After administering, tallying, tabulating, and encoding, analyzing the data gathered followed.

The weighted mean is the statistical tool used to describe the result of the survey. This study utilized Kruskal-Wallis test because the nature of the data is not normally distributed therefore, non-parametric test was used to determine if there is a significant difference among the variables when grouped according to demographic profile. Weighted Mean and Ranking were the statistical tools used to describe the following variable: Authentic Dining Experiences in Asian Cuisine Restaurant in terms of Authenticity, Physical Environment, Quality of Food, and Service Quality. Scale: 3.50-4.00: Very Satisfactory (E); 2.50-3.49: Satisfactory (S); 1.50-2.45: Fair $(F)$; 1.00-1.45: Poor $(P)$. All data and information provided by the customers were solely used for this study and should be kept with the utmost confidentiality. The respondents were not required to sign their names to keep their identity confidential, so as the data provided in this study. The owners, managers, and staff of the restaurant who participated were not exposed to the public for security reasons and positioned the reputation of the restaurants in the community.

\section{Results and discussions}

Presented on Table 2 are the responses on the authentic dining experience in terms of authenticity with the composite mean of 3.47. Food authenticity (3.57) ranked first and was rated as Very Satisfactory. This means that the foods served in the Asian restaurants in Camarines sur provide authentic foods. It implies that authentic Asian cuisine restaurants in Camarines Sur are not just providing sumptuous foods, but they are also giving its customers the authenticity of the food they are providing that meets the customers' expectations in terms of 
authentic experience. Authentic Asian cuisine restaurants in Camarines Sur are knowledgeable on the authenticity of the food that they are offering to its customers. It can also be deduced that customers in an authentic Asian cuisine restaurant in Camarines Sur are very satisfied of the authenticity of the food.

Table 2

Authentic dining experience in terms of authenticity

\begin{tabular}{lcccc}
\hline \multicolumn{1}{c}{ Authenticity } & WM & SD & VI & Rank \\
\hline (1) Atmosphere authenticity & 3.43 & 0.62 & S & 2.5 \\
(2) Food authenticity & 3.57 & 0.58 & VS & 1 \\
(3) Authentic menu presentation (traditional descriptions of food) & 3.43 & 0.63 & S & 2.5 \\
Composite Mean & 3.47 & 0.50 & S & \\
\hline
\end{tabular}

Authentic experiences are characterized by sincerity, authenticity, or something that is marked by conformity with a long-standing or generalized tradition. Many people crave an authentic experience when they seek to fully discover a culture or society, including through their local cuisine. An authentic local food consumption experience has become an essential means of generating understanding and awareness of the identity and gastronomic culture of a customer's destination (Ingerson \& Kim, 2016). Perceived authenticity of food strongly influenced customer's experience in Asian restaurants. Customers who perceived Asian food to be authentic were more likely to have positive experience at Asian restaurants which authentic food creates memorable experiences for every customer (Ab Latif, 2018).

The least authenticity parameters were Atmosphere authenticity (3.43) and Authentic menu presentation (traditional description of food) (3.43) that both ranked 2nd, rated as satisfactory. Based on the analysis, restaurants must improve the atmosphere authenticity and its authentic menu presentation to provide a more authentic dining experience among its customers. These points imply that diners frequently visit certain authentic ethnic Asian cuisine restaurants because they value authenticity, and their choice is influenced by how they can be enriched by experiencing a culture.

Atmosphere Authenticity is important because it influences the customers' post-purchase intentions and the "cognitive, emotional and psychological status of the customer". "Atmosphere-related elements into four groups - distinctiveness, hospitability, relaxation and refinement - based on guests' perceptions" (Hernandez, 2019). Atmosphere authenticity influences the customers' post-purchase intentions such as "customer satisfaction, revisit intentions, and word-of-mouth intentions. According to Hernandez (2019), customers place very high importance on what they can see in the menu when there is an array of authentic dishes to choose from and try out. They also consider the portion size of the food fairly important to them because most of the dishes served in authentic ethnic Asian cuisine restaurants are sumptuous. He further added that menu is the most important representation of a restaurant. Authentic Asian cuisine restaurants showcase sumptuous offering based on the presentation of their food traditionally. Varieties of food items must be clearly seen on their menu items because of its traditional and meticulous way of preparations. Good selection and range of menu items in most Filipinos are primary because of their desire for varieties of dishes.

Table 3

Authentic dining experience in terms of physical environment

\begin{tabular}{lcccc}
\hline \multicolumn{1}{c}{ Physical Environment } & WM & SD & VI & Rank \\
\hline (1) Interior design and décor & 3.38 & 0.64 & $\mathrm{~S}$ & 4 \\
(2) Appropriate room temperature. & 3.38 & 0.67 & $\mathrm{~S}$ & 3 \\
(3) Noise level & 3.11 & 0.76 & $\mathrm{~S}$ & 5 \\
(4) Restaurant cleanliness & 3.39 & 0.68 & $\mathrm{~S}$ & 2 \\
(5) Neat and well-dressed employees & 3.51 & 0.64 & $\mathrm{VS}$ & 1 \\
\multicolumn{1}{c}{ Composite Mean } & 3.35 & 0.52 & $\mathrm{~S}$ & \\
\hline
\end{tabular}

Table 3 shows that the composite mean of the Authentic dining experience in terms of Physical Environment 
was 3.35. The result indicates that Neat and well-dressed employees (3.51) topped among the parameters and was verbally interpreted very satisfactory and followed by Restaurant cleanliness (3.39) as ranked 2nd and verbally interpreted as Satisfactory. This implies that employees of Asian restaurants in Camarines Sur are presentable when interacting with customers that they are in their proper uniforms and are well-groomed.

In restaurants, the physical environment plays an important role in the success and the post-purchase intentions of the customers (Githiri, 2017; Magnini \& Parker, 2009). The desire to eat in a better and healthier setting has increased in recent years (Ryu \& Han, 2010). The physical environment of the service providers becomes more important in this situation (Maeng \& Park 2015). To offer their customers Being neat and well dress is a must for service companies to be strong and competitive. According to Tuzunkan and Albayrak (2016), the value of the fitness setting on its significance for the physical environment.

Meanwhile the following parameters were rated as Satisfactory: Appropriate room temperature (3.38) ranked 3rd, Interior design and décor ranked (3.38) 4th and, Noise level (3.11) ranked 5th as the least among the five parameters. Based on the researcher's observation, most of the authentic Asian cuisine restaurants are not conducive for the customers since most of these restaurants are having small spaces as dining area while providing louder music background. Service is abstract (Kotler et al., 2006) and regular presentation is required. This method requires customers. Service quality and the physical atmosphere (for example, the presence of lighting, decorations, configurations and personnel) need to be appropriate in food establishments. Nonetheless, a major effect on custody satisfaction and quality of services can be seen by its physical climate in the restaurant sector (Ryu \& Han, 2010; Ryu \& Jang, 2007; Kotler, 1973).

The customer satisfaction is also accomplished by the physical environment (Seo et al., 2015). The study further claimed that the physical environment affects not only the decision of the consumer before purchase but also products and services' quality and satisfaction relevant to the after purchase. The physical environment in the service sector has recently been tried by researchers. As initial insight into the atmosphere within the service area as "art works, symbols and sign sizes, temperature, sound, lighting, background music, layout of office furniture, vendors, appliances, service areas and corridors, room connections, and arrangements". The physical environment in restaurants has dimensions such as service staff, esthetics, architecture and ambiances, table layout and lighting, Tuzunkan and Albayrak (2016). The DINESCAPE scale has been utilized by Ryu and Han (2010) to measure the physical dimensions of the restaurant setting. DINESCAPE is described in the dining area of luxury restaurants as the physical and human atmosphere.

\section{Table 4}

Authentic dining experience in terms of quality of food

\begin{tabular}{lcccc}
\hline \multicolumn{1}{c}{ Quality of Food } & WM & SD & VI & Rank \\
\hline (1) Food presentation & 3.61 & 0.56 & VS & 3 \\
(2) Food taste & 3.64 & 0.56 & VS & 1 \\
(3) Food freshness & 3.61 & 0.58 & VS & 3 \\
(4) Appropriate food temperature & 3.61 & 0.59 & VS & 3 \\
(5) Drink taste & 3.50 & 0.61 & VS & 5 \\
& Composite Mean & 3.59 & 0.47 & VS \\
\hline
\end{tabular}

Table 4 presents the authentic dining experience in terms of quality of food with a composite mean of 3.59 of "very satisfactory". The result shows that food taste obtained a weighted mean of 3.64 as the top one followed by food presentation, food freshness, and appropriate food temperature with the same weighted mean of 3.61 ranking as third. It implies that the quality of service plays a great role in the authentic dining experience of the customers in an Asian restaurant. This only means that Asian restaurants in Camarines Sur provides excellent and sumptuous foods and customers are very much happy with the overall quality of food served. The standard of food also decides customer satisfaction in restaurants and the most important factor affecting satisfaction was food quality and the only factor predicting post-purchase intentions (Nor, Binti, Ahmad Shariff et al., 2015). They also assessed the relationships of individual food quality attributes such as "food presentation", "menu 
selection", "healthier choices", "taste", "freshness of food", and "temperature" with post-purchase intentions. Food quality is one of the main determinants of the authentic dining experiences of customers and a significant factor that influences customer satisfaction and post-purchase intentions (Kim et al., 2017). The least among the parameter is the drink taste (3.50) that ranked fifth which was rated as very satisfied. This means that customers are not after the drinks though they are very satisfied with it. They are after the foods they eat rather than to what they are drinking in an Asian cuisine restaurant. This is supported by the study of Hernandez (2019), which revealed that drinks as the least important pulls motivators. This suggests that diners are pulled to a restaurant because they receive good service, and the menu offers food that the diner is seeking, rather than because the restaurant has the right type of drinks.

\section{Table 5}

Authentic dining experience in terms of service quality

\begin{tabular}{lcccc}
\multicolumn{1}{c}{ Service Quality } & WM & SD & VI & Rank \\
\hline 1) Friendly \& courteous employees & 3.55 & 0.60 & VS & 3 \\
(2) Prompt service & 3.45 & 0.63 & S & 5 \\
(3) Helpful employees. & 3.54 & 0.62 & VS & 4 \\
(4) Employees have knowledge of the products offered & 3.58 & 0.58 & VS & 2 \\
(5) Waiting time before food arriving & 3.36 & 0.68 & S & 6 \\
(6) Food served as ordered & 3.60 & 0.57 & VS & 1 \\
& Composite Mean & 3.51 & 0.50 & VS \\
\hline
\end{tabular}

Table 5 reveals that customers of Asian restaurants in Camarines Sur are very satisfied with the Authentic dining experience in terms of Service quality as indicated by the composite mean of 3.51. Food served as ordered (3.60) ranked first among the parameters followed by and employees have knowledge of the products offered (3.58) that ranked 2nd and Friendly and courteous employees (3.55) that ranked 3rd.These were rated as very satisfied. This means that Authentic Asian cuisine restaurants in Camarines Sur are reliable and accurate in providing service to its customers. Authentic Asian restaurants provide foods as what their customers expects. In addition, service quality plays a great role in the authentic dining experience of the customers in an Asian restaurant. According to Aftab and Sarwar (2016), "reliability in restaurants referred as providing service as promised, on-schedule food delivery and fair charges for food. It is noticed that being reliable is an exceptionally vital quality to have, particularly in the fast-food industry".

In these restaurants, the customers still care a lot about the people they encounter. They should be warm, friendly and supportive. It may be true that diners typically search for the best facilities in town, but customers often expect first-rate welcoming service, initiative, and productive employees (Hernandez, 2019). One of Parasuraman's most important results is that the standard of service can be measured by measuring customer expectations to their impressions of the actual service experience. That is, the quality of service is the product of the discrepancy between the standards of service and the perceptions of customers about actual service. The quality of service is also said to contribute to improved customer satisfaction and loyalty (Al-Tit, 2015). The least among the parameters are helpful employees (3.54) that ranked 4th verbally interpreted as very satisfactory, followed by prompt service (3.45) that ranked 5th verbally interpreted as satisfactory and waiting time before food arriving (3.36) which ranked 6th and verbally interpreted as satisfactory. This means that the authentic Asian cuisine restaurant in Camarines Sur needs to improve their timely service to its customers because customers appreciate quick service when they eat in a restaurant. Aftab and Sarwar (2016) said that "responsiveness is characterized as the extent to which service providers are willing to accommodate clients and provide timely service. Eagerness to assist clients and offer quick service is known as responsiveness. Providing service in a timely manner is highly appreciated by customers." If the consumers are satisfied with the services the company provides customer responsiveness, this would create good intentions for the consumers and generate a high level of loyalty intention for the customer. According to Uyoga (2018), responsiveness as a core dimension of service quality such as "employee responsiveness to the demands and requests" and "timely customer care". 


\section{Table 6}

Summary of the dining experience in the authentic ethnic Asian cuisine restaurants

\begin{tabular}{lcccc}
\hline \multicolumn{1}{c}{ Dining Experience } & WM & SD & VI & Rank \\
\hline Authenticity & 3.47 & 0.50 & S & 3 \\
Physical Environment & 3.35 & 0.52 & S & 4 \\
Quality of Food & 3.59 & 0.47 & VS & 1 \\
Service Quality & 3.51 & 0.50 & VS & 2 \\
\hline
\end{tabular}

Table 6 reveals that customers of Asian restaurants in Camarines Sur are Very Satisfied with Quality of Food (3.59) that is ranked 1st and Service Quality (3.51) that ranked 2nd. This means that Asian restaurants provide exceptional quality of food and service to their customers that lead to satisfaction. The authentic Asian cuisine restaurants met and exceeded the expectation of the customers to the foods and services offered. Food quality plays an important role in the food service industries. The quality of food compared to the quality of raw materials, both are helpful in improving the menu's effectiveness and will become the restaurant's selling tool. Food quality is one of the variables in the development of the customers in various restaurant categories. Customers indicate their desire to come to the restaurant for food taste and return due to food quality in the future. If quality of food is high, costumers are willing to pay extra and give incentives and tips to the restaurant service. The consistency of the food has a positive effect on consumer satisfaction. The result indicates that the relationship between quality of service and quality of food has a significant effect on consumer satisfaction, which will improve customer retention in the future. Service quality has been ranked second important factor in the hospitality industry which customers decide to return to restaurant. Quality of service and customer loyalty is both considerations for any company to succeed. Hospitality industry is investing tremendously to boost the quality of service, so that consumers can stay loyal to the company. A completely satisfied consumer just promotes your Word to Mouth (WOM) products which have no costs (Kumar \& Bhatnagar, 2017).

On the other hand, customers are satisfied with Authenticity (3.47) which ranked 3rd and Physical Environment (3.35) that ranked 4th, which is the least among the four parameters. This shows that restaurants need to improve their physical environment to exceed the expectations of the customers. Restaurants are lacking a conducive and cozy environment for the customers. DINESCAPE's dimensions as an esthetic element, environment, lighting, service product, layout and social considerations were decided. The DINESCAPE dimensions scale for aesthetics, lighting, climate, layout, table configurations and service personnel were created by the Mahalingam et al. (2016). Ryu and Jang (2007) analyzed the impact of dinner on the behavioral preferences, as perceived by their feelings, of consumers in luxury restaurants. The physical dimensions of the building are defined in six dimensions, as services, lamps, climate, layout, restaurants, and workers in their analysis. Unal et al., (2014) used the restaurant atmosphere term in their studies rather than the description of the physical world. They determined 4 dimensions, including lighting \& climate, architecture, general design and dine equipment $\&$ furniture, as the dimension of the atmosphere in a restaurant. In their research Ayazlar and Gün (2017) have defined the physical environment dimensions of restaurants as esthetics, decor, lighting, table setting, layout and service teams. Güzel (2017) examined customer reviews on Tripadvisor on the role of the physical environment in first-class Istanbul restaurants. In his report, Güzel (2017) analyzed the comments on the physical environment in terms of the dimensions of the employee, climate, settlement and landscape and concluded that the customers commented primarily on the dimension of "climate."

Table 7

Significant differences in the authentic experiences when grouped according to current dining

\begin{tabular}{lccccc}
\hline \multicolumn{1}{c}{ Current Dining } & Chinese & Japanese & Korean & $\mathrm{x}^{2}$ & $p$-value \\
\hline Authenticity & 160.46 & 210.10 & 175.72 & $9.263^{*}$ & .010 \\
Physical Environment & 168.17 & 233.80 & 162.39 & $20.048^{* *}$ & .000 \\
Quality of Food & 163.95 & 213.66 & 171.79 & $9.773^{* *}$ & .000 \\
Service Quality & 153.25 & 216.46 & 179.84 & $15.702^{* *}$ & .000 \\
\hline
\end{tabular}

Note. *Significant at $p<.05 ; d f=2$; Kruskal Wallis Test. 
There is a significant difference in the authentic experiences when grouped according to current dining restaurant. Those respondents who are currently dining in Japanese restaurants have significantly higher response in the authentic experiences in terms of authenticity as indicated by the computed $x^{2}=9.263, p=.010$; as well as in physical environment, $\mathrm{x}^{2}=20.048, p<.000$; quality of food, $\mathrm{x}^{2}=9.773, p<.000$; and service quality, $\mathrm{x}^{2}=15.702, p<.000$, compared to those customers who are currently dining in Chinese and Korean restaurants.

The results show that the customers really appreciate the overall Authentic dining experience in terms of authenticity, physical environment, quality of food, and service quality as they dined in the Asian restaurant in Camarines Sur. Asian restaurants in Camarines Sur are providing and performing well in giving the best experience among their customers. Japanese restaurants have significantly higher response in the authentic experiences in terms of authenticity for the reason of Japanese food, where the dining experience is not only about the actual food consumed, but also the presentation, the design, the sheer beauty of what you're eating. Noll (2019) further said that there are rules in traditional Japanese cuisine, as in Japanese life. Governments on food. Meals are divided into bowls and pans, and subdivided further, all in an attempt to distinguish flavors so that they do not affect each other. This is consistency on a plate. In Japan, beauty is important, from the many porcelain plates and bowls you might eat one meal from, to the tray landscape on which it is all served. There's logic, in every facet of the dining experience, in every item in the meal, there is intent, built by built, compare this with other East Asian cuisines where large pots from the middle of the table are shared. Japanese food is meticulous, that is, full of attention.

\section{Table 8}

Significant differences on the respondents' authentic experience in terms of cuisine preference

\begin{tabular}{lccccc}
\hline \multicolumn{1}{c}{ Korean Preference } & First & Second & Third & $\mathrm{x}^{2}$ & $p$-value \\
\hline Authenticity & 176.80 & 168.06 & 178.35 & .623 & .732 \\
Physical Environment & 172.05 & 176.72 & 180.08 & .322 & .851 \\
Quality of Food & 173.09 & 171.75 & 186.10 & .828 & .661 \\
Service Quality & 173.04 & 174.75 & 180.05 & .199 & .905 \\
Chinese Preference & & & & & .311 \\
Authenticity & 170.07 & 177.81 & 173.50 & .856 \\
Physical Environment & 175.58 & 179.91 & 168.96 & .857 & .651 \\
Quality of Food & 182.40 & 174.60 & 170.70 & .689 & .709 \\
Service Quality & 171.26 & 172.04 & 178.31 & .379 & .827 \\
Japanese Preference & & & & & .441 \\
Authenticity & 182.26 & 165.25 & 176.46 & 1.639 & .402 \\
Physical Environment & 179.47 & 164.00 & 178.98 & 1.821 & .510 \\
Quality of Food & 182.30 & 166.59 & 175.36 & 1.346 & .882 \\
Service Quality & 178.75 & 172.41 & 172.67 & .250 & \\
\hline Note $*$ Significant at $p<05 ; d f=2 ;$ Kruskal Wallis Test. & & & &
\end{tabular}

No significant difference exists on the respondents' authentic experience when grouped according to preferences as indicated by the computed $p$-values which are all greater than .05 alpha level. This signifies that no matter what the customers' preference of restaurants, they have diverse response in terms of authentic experience. Customers of Asian restaurant are looking for the best authentic experiences when dining in no matter what their cuisine preferences. They just want to enjoy the overall experience. According to Kalalo et al. (2014), the way people eat, the process of preparing food and the taste of food, differentiate the culture. Thus, different Customers food consumption may be due to experience with other cultures. Culinary tourism encompasses the dining experience beyond. It includes a variety of culinary items, developed specifically for Customers showcasing food and drinks. This also gives visitors the opportunity to discover indigenous dishes in each region, while learning about their unique talents and creativity.

There is no significant difference on the Customers' Authentic Experience in terms of authenticity $\left(x^{2}=9.787\right.$, $p=.081)$ and physical environment $\left(x^{2}=9.787, p=.081\right)$ when grouped according to number of visit. This signifies that no matter how many times they visited these Asian Cuisine Restaurants, their responses do not vary 
significantly. However, Significant difference exists on quality of food $\left(x^{2}=13.204, p=.022\right)$ and service quality $\left(x^{2}=11.75, p=.038\right)$. Results showed that those customers who visited three times the Asian Cuisine Restaurants have significantly higher response on quality of food compared to those who visited twice. Furthermore, those who visited once have significantly higher response on service quality than those who visited twice.

Table 9

Significant differences on the customers' authentic experience in terms of number of visit

\begin{tabular}{lccccccc}
\hline \multicolumn{1}{c}{ Number of visit } & 1 & 2 & 3 & 4 & 5 & $>5$ & $X^{2}$ \\
\hline Authenticity & 200.81 & 155.50 & 188.94 & 156.63 & 186.22 & 167.14 & 9.787 \\
Physical environment & 188.65 & 161.13 & 180.28 & 192.63 & 155.62 & 174.00 & 4.414 \\
Quality of food & 179.34 & 139.43 & 193.43 & 189.13 & 162.62 & 184.30 & $13.204 *$ \\
Service quality & 194.19 & 141.90 & 184.06 & 189.17 & 191.57 & 172.23 & $11.750^{*}$ \\
\hline
\end{tabular}

Note. ${ }^{*}$ Significant at $p<.05 ; d f=5$; Kruskal Wallis Test.

From the results, it can be inferred that Asian cuisine restaurant customers in Camarines Sur are more meticulous about the quality of the food and service. In terms of food quality, customers get excellent food every time they visit the Asian restaurants and this only shows that Asian restaurants in Camarines Sur respect their loyal customers by always offering the best food to sustain customer satisfaction. On the other hand, customers who visited twice have a slightly lower response compared to those who visited once, it indicates that customers demand more from quality service as they revisit Asian restaurants in Camarines and the restaurants have to give an extra mile to keep their customers satisfied and happy. As customers regularly visit, their standards for quality service are higher.

As discussed in the previous discussion, it is stated from the analysis of Nor et al. (2015) that "providing fresh, tasty, correct food service, food temperature and a variety of foods and beverages remains an important criterion for satisfying the clients". Their research identified that food quality has widely been acknowledged as a major factor affecting post-purchase intentions of the customers. Food quality is an important factor affecting consumer loyalty and post-purchase intent (Kim et al., 2017). They should be friendly, accommodating, and serviceable. It may be true that diners usually look for the best facilities in town, but customers also expect first-rate service welcoming, initiative, and efficient staff (Hernandez, 2019). It is quoted from the study of Al-Tit (2015), "service quality can be assessed by comparing the expectations of customers against their perceptions of the actual service experience. That is, service quality is an outcome of the difference between service expectations and customer perceptions of actual service. It is also said that service quality leads to enhanced customer satisfaction and loyalty."

From Business Queensland article (2020), Customer Service is about offering customers in the best possible way what they want, when they want it. If Asian restaurant offers good customer service, the chances of keeping and growing the customer base will be greater. Good customer service can help Asian restaurants grow by increasing customer numbers through favorable word-of - mouth advertising; the dollar amount spent per transaction per customer and; the frequency of customer visits. Establishing a culture of excellent customer service in Asian restaurants is through the preparation, implementation and maintenance of a customer service program. Training the workers to provide the highest quality of service to customers is a must. This then shows that Authentic dining experiences perceived values can have a high impact on customer satisfaction and post-purchase intentions. The utilitarian value can also be said to have a stronger impact on customer satisfaction and positive behavioral intentions than the hedonic value (Hernandez, 2019).

No significant difference exists on the authenticity $\left(x^{2}=2.137, p=.545\right)$, physical environment $\left(x^{2}=2.757\right.$, $p=.431)$, and quality of food $\left(x^{2}=3.914, p=.271\right)$ when grouped according to dining expenses. However, significant difference exists on service quality $\left(x^{2}=7.962, p=.047\right)$. Result showed that those customers with more than $\mathrm{P} 3,000$ dining expenses have significantly higher response on the service quality than those with less than P3,000. This only shows that the higher the dining expenses, the higher the service quality expectation of the customers to the Asian cuisine restaurants in Camarines Sur. It is because, as customers spend money, they 
Authentic dining experiences of ethnic Asian cuisine restaurant customers in Camarines Sur

expect that their spending would be worth it and valued and the service would also be met or it will exceed the value of the money they spend. In terms of price expectations nexus, customers do pay for services with expectations their quality is worth the payments.

\section{Table 10}

Significant differences on the customers' authentic experience in terms of dining expenses

\begin{tabular}{lcccccc}
\hline \multicolumn{1}{c}{ Dining Expenses } & $<1,000$ & $<2,000$ & $<3,000$ & $>3,000$ & $\mathrm{x}^{2}$ & $p$-value \\
\hline Authenticity & 168.40 & 184.18 & 173.24 & 189.55 & 2.137 & .545 \\
Physical Environment & 171.31 & 185.37 & 160.35 & 189.33 & 2.757 & .431 \\
Quality of Food & 171.52 & 187.21 & 156.73 & 188.07 & 3.914 & .271 \\
Service Quality & 169.37 & 185.46 & 154.97 & 218.93 & $7.962 *$ & .047 \\
\hline
\end{tabular}

Note. *Significant at $p<.05 ; d f=3$; Kruskal Wallis Test.

This may have to do with Muskat research et al. (2019), the standard of service has a strong effect on the intentions of satisfaction and post-purchase. Su et al. (2016), establishes clear ties between service quality, consumer loyalty and customer business identity, which positively affects intention to buy back and customer well-being. However, studies suggest that the relationship between high-quality service and consumer satisfaction and behavioral intentions depends on the restaurant form and the customer profile, such as dining costs. It is also found that different levels of service quality (below average, average, and above average) for upscale restaurants would only increase customer return intentions when they have an above average service. Furthermore, consumer satisfaction is higher when the level of service is high than resulting in the perception of the customer earning greater value for the price paid (Namin, 2017).

\section{Conclusion and recommendation}

The customer-respondents are very satisfied with the food authenticity in terms of authenticity, Neat and well-dressed employees in terms of physical environment. The customers- respondents are very satisfied with the overall food quality and service quality of the Asian restaurants in Camarines Sur. There is a significant higher difference in the authentic dining experiences when grouped according to current dining place on Japanese restaurants, and there is a significant difference on the customers' authentic experience in terms of number of visits in food quality and service quality. There is also a significant difference on the customers' authentic experience in terms of dining expenses in service quality.

Restaurateurs of authentic ethnic Asian cuisine restaurants may improve their dining experiences in terms of Authenticity and Physical environment because these are core attributes in an overall authentic dining experience of the customers. Providing an extra mile on their services may exceed the customer expectation and satisfaction by improving their responsiveness. They may also give more information about the drinks they are offering since customers are not much into the drinks. Restaurateurs must also identify what music could suit their customer's tastes. Sending employees to a service quality related training seminar may help improve the standards in operating the business. Employees can be trained with respect to the quality-of-service interactions and emotional displays in front of the customer. Restaurant managers should also put in place quality control procedures to ensure that Customers receive not only consistent service but also ethnic food of the highest quality. They may be trained to American Hotel and Lodging Educational Institute (AHLEI) to improve their services for the customers.

\section{References}

$\mathrm{Ab}$ Latif, Z. (2018). The effect of perceived authenticity of food towards experience and place attachment at the State Fair (Publication No. 16909) [Graduate Theses and Dissertations]. https://lib.dr.iastate.edu/etd/16909

Aftab, J., \& Sarwar, H. (2016). Importance of service quality in customer satisfaction: A study on fast food restaurants. Entrepreneurship and Innovation Management Journal, 4, 161-171. 
Agarwal, R., \& Dahm, M. J. (2015). Success factors in independent ethnic restaurants. Journal of Foodservice Business Research, 18(1), 20-33. https://doi.org/10.1080/15378020.2015.995749

Al-Tit, A. (2015). The effect of service and food quality on customer satisfaction and hence customer retention. Asian Social Science, 11, 129-139. https://doi.org/10.5539/ass.v11n23p129

Ayazlar, R. A., \& Gün, G. (2017). Perception of physical environment elements in the restaurant [Restorandaki Fiziksel Çevre Unsurlarının Algılanması]. Journal of Tourism and Gastronomy Studies, 5(2), 138-150. https://doi.org/10.21325/jotags.2017.118

Business Queensland. (2020). Principles of good customer service. https://www.business.qld.gov.au/

Githiri, M. N. (2017). Influence of physical environment on customer satisfaction and return intention in Kenyan rated restaurants. Asian Journal of Social Science Studies, 2(1), 11-19. https://doi.org/10.20849/ajsss.v2i1.82

Güzel, S. Ö. (2017). Evaluation of physical environmental elements in first class restaurant businesses in terms of customer comments: Trip advisor example. [Birinci Sınıf Restoran İşletmelerindeki Fiziksel Çevre Unsurlarının Müşteri Yorumları Açısından Değerlendirilmesi: Tripadvisor Örneği]. Akademik Sosyal Araştırmalar Dergisi, 5(62), 534-542. https://doi.org/10.16992/ASOS.13258

Han, H., \& Hyun, S. S. (2017). Impact of hotel-restaurant image and quality of physical-environment, service, and food on satisfaction and intention. International Journal of Hospitality Management, 63, 82-92. https://doi.org/10.1016/j.ijhm.2017.03.006

Han, H., \& Ryu, K. (2009). The roles of the physical environment, price perception, and customer satisfaction in determining customer loyalty in the restaurant industry. Journal of Hospitality \& Tourism Research 33(4), 487-510. https://doi.org/10.1177/1096348009344212

Hernandez, G. R. (2019). A proposed restaurateur-costumer framework for authentic ethnic [Dissertation. Lyceum of the Philippines University]. Batangas City, Philippines.

Higgs, S., \& Thomas, J. (2016). Social influences on eating. Current Opinion in Behavioral Science, 9, 1-6. https://doi.org/10.1016/j.cobeha.2015.10.005

Ingerson, S., \& Kim, A. (2016). Exploring the value of an ethnic restaurant experience: A consumer perspective towards Korean restaurants. Tourism Recreation Research, 41, 1-14.

https://doi.org/10.1080/02508281.2016.1151163

Jang, S. S., \& Namkung, Y. (2009). Perceived quality, emotions, and behavioral intentions: Application of an extended Mehrabian-Russell model to restaurants. Journal of Business Research, 62(4), 451-460. https://doi.org/10.1016/j.jbusres.2008.01.038

Kalalo, R., Cablao, A., Cabatay, M., Mantal, C., Manalo, R., \& Felicen, S. (2014). Cuisine preference of local tourists in San Juan, Batangas, Philippines. Asia Pacific Journal of Multidisciplinary Research, 2(4), 101-111.

Kim, D. (2018). Causes, experiences, and consequences of ethnic food consumption: A case study of Korean Restaurants in Sweden [Masteral Thesis].

Kim, J. H., Youn, H., \& Rao, Y. (2017). Customer responses to food-related attributes in ethnic restaurants. International Journal of Hospitality Management, 61, 129-139. https://doi.org/10.1016/j.ijhm.2016.11.003

Kotler, P., Bowen, J., \& Makens, J. (2014). Marketing for hospitality and tourism. Pearson.

Kumar, S., \& Bhatnagar, D. D. (2017). Factors affecting customer satisfaction of food and beverage outlets: A study of food and beverage outlets between Amritsar and Jalandhar. IOSR Journal of Humanities and Social Sciences, 22(9), 65-71.

Maeng, H. K., \& Park, J.W. (2015). A study on the effect of the physical environment in an airplane on customer loyalty. Journal of Airline and Airport Management, 5. https://doi.org/10.3926/jairm.47

Magnini, V., \& Parker, E. (2009). The psychological effects of music: Implications for hotel firms. Journal of Vacation Marketing, 15, 53-62. https://doi.org/10.1177/1356766708098171

Mahalingam, S., Jain, B., \& Sahay, M. (2016). Role of physical environment (Dinescape factors) influencing customers' revisiting intention to restaurants. In 2016 International Conference on Advances in Computing, communications and Informatics (pp. 1069-1072). 
Authentic dining experiences of ethnic Asian cuisine restaurant customers in Camarines Sur https://doi.org/10.1109/ICACCI.2016.7732186

Muskat, B., Hörtnagl, T., Prayag, G., \& Wagner, S. (2019). Perceived quality, authenticity, and price in tourists' dining experiences: Testing competing models of satisfaction and behavioral intentions. Journal of Vacation Marketing. https://doi.org/10.1177/1356766718822675

Nam, M. J., Shim, C., \& Jeong, C. (2017). The effect of food quality on behavioral intention in Korean restaurants: From the perspective of Chinese Customers. International Journal of Tourism and Hospitality Research, 31, 59-72. https://doi.org/10.21298/IJTHR.2017.10.31.10.59

Namin, A. (2017). Revisiting customers' perception of service quality in fast food restaurants. Journal of Retailing and Consumer Services, 34, 70-81. https://doi.org/10.1016/j.jretconser.2016.09.008

Namkung Y., \& Jang, S. (2007). Does food quality really matter in restaurants? Its impact on customer satisfaction and behavioral intentions. Journal of Hospitality and Tourism Research, 31(3), 387-409. https://doi.org/10.1177/1096348007299924

Noll, D. (2019). Japanese food: From tempura to takoyaki. World Cuisine Guide. https://doi.org/www.uncorneredmarket.com

Nor, S., Binti, F., Ahmad Shariff, S. N. F., Binti, M., Siti Nurhanifah, S., Sulong, B., Adilin, H., Mohd, B., Majid, A., Binti, H., Ibrahim, M., Jaafar, Z., Muhamad, S. K., Omar, B., \& Muhamad, K. S. (2015). The influence of service quality and food quality towards customer fulfillment and revisit intention. Canadian Social Science, 11, 110-116. https://doi.org/10.3968/7369

Omar, M., Ariffin, H., \& Ahmad, R. (2015). The relationship between restaurant ambience and customers' satisfaction in Shah Alam Arabic Restaurants, Selangor. International Journal of Administration and Governance, 1, 1-8.

Ryu, H., \& Jang, S. (2007). The effect of environmental perceptions on behavioral intentions through emotions: The case of upscale restaurants. Journal of Hospitality \& Tourism Research, 31, 56-72. https://doi.org/10.1177/1096348006295506

Ryu, K., \& Han, H. (2010). Influence of the quality of food, service, and physical environment on customer satisfaction and behavioral intention in quick casual restaurants: Moderating role of perceived price. Journal of Hospitality \& Tourism Research, 34(3), 310-329. https://doi.org/10.1177/1096348009350624

Su, L., Swanson, S. R., Chinchanachokchai, S., Hsu, M. K., \& Chen, X. (2016). Reputation and intentions: The role of satisfaction, identification, and commitment. Journal of Business Research, 69(9), 3261-3269. https://doi.org/10.1016/j.jbusres.2016.02.023

Tuzunkan, D. (2016). The importance of restaurant physical environment for Turkish customers. Journal of Tourism Research and Hospitality, 5. https://doi.org/10.4172/2324-8807.1000154

Ünal, S., Akkuş, G., \& Akkuş, Ç. (2014). The relationship of atmosphere, emotion, satisfaction and behavioral loyalty in food and beverage business [Yiyecek İçecek İşletmelerinde Atmosfer, Duygu, Memnuniyet ve Davranışsal Sadakat İlişkisi]. Gazi Üniversitesi Turizm Fakültesi Dergisi, 1, 23-49.

Uyoga, D. (2018). Relationship between customer responsiveness, service performance and satisfaction among airline passengers in Kenya. Journal of Emerging Trends in Economics and Management Sciences, $10(2), 61-69$.

Zhong, Y., \& Moon, H. C. (2020). What drives customer satisfaction, loyalty, and happiness in fast-food restaurants in China? Perceived price, service quality, food quality, physical environment quality, and the moderating role of gender. Foods, 9(4), 460. https://doi.org/10.3390/foods9040460 
Illo, N. P. 